\title{
Priority Information Determining the Canonical Word Order of Written Sinhalese Sentences
}

\author{
Arachchige Buddhika Prabath Kanduboda, Katsuo Tamaoka \\ Graduate School of Languages and Cultures, Nagoya University, Aichi, Japan \\ Email: kanduboda80@gmail.com, ktamaoka@gc4.so-net.ne.jp
}

Received February $10^{\text {th }}, 2012$; revised March $9^{\text {th }}, 2012$; accepted March $16^{\text {th }}, 2012$

\begin{abstract}
The present study investigated the priority of information among case particles, thematic roles or grammatical functions in determining the canonical SOV word order of written Sinhalese. Four types of sentences were given to native Sinhalese speakers to perform sentence correctness decisions. The active sentences with transitive verbs in Experiment 1 and with ditransitive verbs in Experiment 2 revealed that canonical sentences (i.e., SOV or SOOV) were processed more quickly and accurately than the scrambled sentences (i.e., OSV or OSOV), which supported the existence of scrambling effects. However, since thematic roles, case particles and grammatical functions provide the same information for the SOV canonical order, two further experiments were conducted to single out the priority of information. In Experiment 3, native Sinhalese speakers processed passive sentences with canonical word order defined by case particles (i.e., SOV) more quickly and accurately than those defined by thematic roles (i.e., OSV). In Experiment 4, native speakers processed potential sentences defined by grammatical functions (i.e., SOV) more quickly and accurately than the information provided by case markers (i.e., OSV). Therefore, the present study concluded that grammatical functions play a crucial role to determine SOV canonical order.
\end{abstract}

Keywords: Canonical Order; Sinhalese; Priority Information; Thematic Roles; Case Markers; Grammatical Functions

\section{Introduction}

The Sinhalese language is one of three official languages spoken in Sri Lanka (others being Tamil and English), and has a history of more than two thousand years. Sinhalese has two distinct forms of spoken and written, within the single language. The written and spoken forms differ noticeably in their core grammatical structures (Englebretson \& Genetti, 2005; Miyagishi, 2005). For example, the subject in the spoken form in a subordinate clause is marked by nominative, whereas in the written form the subject is marked by accusative (Miyagishi, 2005). The spoken form is mostly used in daily life and other casual speech, whereas in reading news on TV or radio as well as for other printed material such as news papers, the written form is mostly used. While the spoken form is very flexible in various syntactic aspects, the written form involves many grammatical rules (Dissanayaka, 2007). The present study focuses only on written form.

Word order in the Sinhalese language is said to be subject (S) object (O) and verb (V) (Dissanayaka, 2007; Herath, Hyodo, Kawada, Ikeda, \& Herath, 1994; Pallatthara \&Weihene, 1966). Furthermore, previous studies on the Sinhalese language (e.g., Dissanayaka, 2007; Gair, 1998; Miyagishi, 2003) suggest that the flexibility of Sinhalese word order allows sentences to have another five different word orders as OSV, OVS, SVO, VSO, and VOS which also represent the same meaning of that SOV ordered sentence. Tamaoka, Kanduboda, \& Sakai (2011) conducted experiments using all these orders. They found that, among them, SOV is the fastest to be processed by native Sinhalese speakers, and concluded that SOV is the canonical order from the psycholinguistic perspective. Then, the question rose what is the fundamental information which determines SOV as canonical order of Sinhalese sentences. Therefore, using sentences of the written form, the present study investigated the potential information of case particles, sematic roles, and grammatical functions, which provide efficient information for canonical order in the Sinhalese language.

\section{Background and Assumptions}

Scrambling is a term used in linguistic studies for observable facts with free word order (originally proposed by Ross, 1967). Due to the free word order phenomena in Sinhalese, its canonical word order (SOV) can possibly be re-ordered by scrambling transformation. For example, sentence 1) represents a canonically (SOV) ordered active sentence with a transitive verb, Kamala hit Nimala. Simply altering between S and O, scrambled OSV order of 2) results.

1) SOV order (canonical)

kamalā nimala-ta gehuwāya

Kamala ( $\varphi$ NOM, anim) Nimala (DAT, anim) hit $(\mathrm{V}+\mathrm{PST})$

Kamala hit Nimala.

2) OSV order (scrambled)

nimala-ta kamalā gehuwāya

Nimala (DAT, anim) Kamala ( $\varphi \mathrm{NOM}$, anim) hit (V + PST)

Kamala hit Nimala.

Canonical order can be identified by three information cues of case particles, sematic roles, and grammatical functions (Tamaoka, Sakai, Kawahara, Miyaoka, Lim, \& Koizumi, 2005). In fact, the SOV canonical order 1) satisfies all this information. First, case particles suggest that a nominative case marker pre- 
cedes an accusative or a dative case marker. The usage of Sinhalese case markers suggests that the word order of active sentence with a transitive verb must be [ $\varphi$ NOM [ACC or DAT V]]. Second, thematic roles suggest that the word order must be arranged in a manner that the agent (Kamala) precedes the patient/receiver (Nimala), and the goal (hit) must be placed at the end. Third, grammatical functions again suggest that the subject (Kamala) should come before the object (Nimala).

On the other hand, the scrambled sentences are assumed to have different order deviated from these information cues. Consider sentence 2) is altered based on 1). Both 1) and 2) carry the same fundamental meaning Kamala hit Nimala. However, sentence 2 ) does not follow any of the three cues; a dative case marker comes before a nominative, a patient comes before an agent, and object comes before subject. Thus, sentence 2) can be considered as a scrambled sentence. Previous studies (e.g., Koizumi \& Tamaoka, 2004, 2010; Mazuka, Itoh, \& Kondo, 2002; Miyamoto \& Takahashi, 2004; Tamaoka, Sakai, Kawahara, Miyaoka, Lim, \& Koizumi, 2005) suggested that canonically ordered sentences were processed faster than scrambled orders. Thus, if native Sinhalese speakers process these two sentences, the canonical SOV order of sentence 1) should be processed faster than the scrambled order of sentence 2). This is tested in Experiment 1 of the present study.

The same argument given to the sentences of 1) and 2) can be made with an active sentence with a dative verb. Both 3) and 4) are Sinhalese active sentences with ditransitive verbs. The word order of example 3) is SOOV (Subject-Indirect ObjectDirect Object, and the Verb). Example 4) is built based upon the word order of 3) in order to have an OSOV scrambled order sentence (Direct Object-Subject-Indirect Object, and the Verb). Despite different word orders, both 3) and 4) fundamentally carry the same meaning of Nimala helped Lalani with studies. As with active sentences consisting of transitive verbs, the three information cues of case markers, thematic roles, and grammatical functions provide the same prediction for the canonical order of ditransitive canonical sentence 3 ). In contrast, sentence 4) deviates all three information cues. Consequently, the canonical order 3 ) should be processed faster than the scrambled order 4). This is tested in Experiment 2 of the present study.

\author{
3) SOOV order (canonical) \\ nimala lalani-ta pādam kiyādunnēya \\ Nimala ( $\varphi$ NOM, anim) Lalani (DAT, anim) study ( $\varphi$ ACC, \\ inam) teach $(\mathrm{V}+\mathrm{PST})$ \\ Nimala helped Lalani with studies. \\ 4) OSOV order (scrambled) \\ pādam nimala lalani-ta kiyādunnēya \\ Study ( $\varphi$ ACC, inam) Nimala ( $\varphi$ NOM, anim) Lalani (DAT, \\ anim) teach (V + PST) \\ Nimala helped Lalani with studies.
}

Two different types of information, thematic roles and case particles provide conflicting information for canonical order for passive sentences with a transitive verb. Considering case markers, sentence 5) is assumed to be canonical since a nominative case-marked noun (computer) is placed in the sentence initial position followed by a dative case-marked noun (Ruwan). In contrast, thematic roles indicate sentence 6) to be canonical, because an agent (Ruwan) comes prior to a theme (computer). In this sense, sentence 6) becomes a scrambled order according to case particles, while sentence 5) is identified as scrambled by thematic roles. Yet, both 5) and 6) fundamentally carry the same meaning of the computer was repaired by Ruwan. These two conflicting sets of information of case particles and thematic roles are tested in Experiment 3 of the present study.

5) SOV order (canonical predicted by case particles) ruwan-wisin pariganakaya hadaadenulebuweaya Ruwan $(\varphi \mathrm{NOM}$, anim) computer $(\varphi \mathrm{ACC}$, inam) repair $(\mathrm{V}+$ PSS + PST)

The computer was repaired by Ruwan.

6) OSV order (canonical predicted by thematic roles)

pariganakaya ruwan-wisin hadaadenulebuweaya

Computer $(\varphi \mathrm{ACC}$, inam) Ruwan $(\varphi \mathrm{NOM}$, anim) repair $(\mathrm{V}+$ PSS + PST)

The computer was repaired by Ruwan.

Once again, different information of case particles and grammatical functions provide conflicting information for canonical order for potential sentences with transitive verbs. According to grammatical functions, the potential sentence 7) is a canonically ordered potential sentence since the subject (Sangiitha) precedes the object (dance). However, according to the case markers, the canonical order should be arranged in a manner that the noun (dance) case-marked by a nominative precede the noun (Sangiitha) with a dative case marker -ta, indicating sentence 8) to be canonical. Again, both sentences 7) and 8) carry the same fundamental meaning of Sangiitha can dance. These two conflicting sets of information of grammatical functions and case particles are tested in Experiment 3 of the present study.

7) SOV order (canonical predicted by grammatical functions) sangiitha-ta natanna hekiyaawaketha

Sangiitha (DAT, anim) dance ( $\varphi$ NOM, inam) can (V + PST)

Sangiitha can dance.

8) OSV order (canonical predicted by case particles)

natanna sangiitha-ta hekiyaawaketha

Dance ( $\varphi$ NOM, inam) Sangiitha (DAT, anim) can (V+PST)

Sangiitha can dance.

Using the fore-mentioned four types of sentences, the present study investigated the priority of information which determines the canonical word order of written Sinhalese. Experiment 1 compared processing of active sentences with transitive verbs between canonical and scrambled orders. Experiment 2 used active sentences with ditransitive verbs, Experiment 3 used passive sentences, and Experiment 4 used potential sentences.

The Sinhalese language is a rare case. There are not many languages existing in the world on which the series of experiments regarding all the three kinds of information of case particles, thematic roles, and grammatical information can be conducted together. The Sinhalese language is one of a few such languages.

\section{Experiment 1: Active Sentences with Transitive Verbs}

Experiment 1 examined active sentences with transitive verbs in order to ascertain the scrambling effects in active sentences with intransitive verbs. Since lexical items used are identical, the processing speeds and errors can be directly compared between canonical and scrambled sentences. Experiment 1 assumed that native Sinhalese speakers would take longer to process OSV scrambled sentences than SOV canonical sentences. Experiment 1 investigated whether or not a dif- 
ferent syntactical structure requires the different degree of cognitive load to process these sentences.

\section{Participants}

Thirty-two native Sinhalese speakers (26 male and 6 female) residing in Japan (Aichi Prefecture) participated in the present experiment. They had been in Japan from 6 months to 3 years of the time of testing. Ages ranged from 23 years and 6 months to 46 years and 4 months, with the average age being 35 years and 0 months on the day of testing. They are all native Sinhalese speakers, born and brought up in Sri Lanka at least up to the age of 21. All of them had fulfilled at least 13 years of education (up to high school graduation) in Sri Lanka instructed in the Sinhalese language. Their Japanese ability was very low; none of them had passed or taken the lowest grade of the Japanese Language Proficiency Test. Among 32 participants, 11 were students at a Japanese language school, and 21 are working at a Japanese company.

\section{Procedure}

Participants were asked to determine as quickly and accurately as possible whether a visually presented sentence in the Sinhalese script on a computer monitor was correct by pressing either a "Yes" key or a "No" key. Reaction times and error rates for sentence correctness decisions were automatically recorded by the computer. The presentation of the stimulus was controlled by a computer program DMDX (version 3.2.6.4). The stimulus sentences were randomly presented in the center of the computer screen for 600 milliseconds after the appearance of a line of asterisks "******" which indicated the eye fixation point on the screen. Prior to the experiment, all the participants were instructed to respond by pressing either "Yes" or "No" key as quickly and as accurately as possible to determine whether the sentence shown on the screen is correct or incorrect. Fourteen practice trials were given to the participants in advance of the actual testing. This procedure was the same in all four experiments and henceforth, explanation will be omitted in the following three experiments.

\section{Materials}

A total of 172 stimuli were prepared for Experiment 1. Thirty-six active sentences with transitive verbs (36 canonical ordered sentences for correct "Yes" responses) were selected according to the canonical order as nominative noun phrase with empty case marker, whereas accusative noun phrase is marked by the dative case marker -ta as in kamala nimala-ta gehuwāya. A sample of "Yes" stimuli are presented in appendix A. In order to make the scrambled order sentences, the nominative NP and the accusative NP were switched as nimala-ta kamalā gehuwāya. There were 36 scrambled sentences for correct "Yes" responses. The same strategy was used to make another 72 stimuli for the correct "No" responses with either syntactically or semantically incorrect sentences. For example, the canonical noun phrase order of amila me-se kéweya meaning "Amila ate the table" is scrambled as me-se amila kêwēya. In this way, 36 canonical and 36 scrambled sentences (72 in total) were created for correct "No" responses. In addition, another 28 (14 canonical sentences and 14 scrambled sentences) sentences were added as control sentences.
To avoid participants repeatedly seeing the same sentences in a different word order, a counterbalanced design was applied to allocate the participants as list 1 and list 2. Each list contained 36 correct (18 canonical and 18 scrambled) sentences for correct "Yes" responses and 36 incorrect (18 canonical and 18 scrambled) sentences for correct "No" responses with an additional 14 control sentences ( 7 canonical and 7 scrambled) to each group.

\section{Analysis and Results}

Extremes among sentence correctness decision times (less than $500 \mathrm{~ms}$ and longer than $5000 \mathrm{~ms}$ ) were recorded as missing values. Table 1 illustrates the means of correct "Yes" and "No" reaction times and error rates for sentence correctness decisions. Before performing the analysis, reaction times outside of 2.5 standard deviations at both the high and low ranges were replaced by boundaries indicated by 2.5 standard deviations from the individual means of participants in each category. Statistical tests were conducted for the participants' variability $\left(F_{1}\right)$ and for the stimulus item variability $\left(F_{2}\right)$. Only stimulus items of correct responses were used in the analyses of reaction times. The means and standard deviations for correct "Yes" and "No" responses are reported in Table 1.

A series of analysis of variance analyses (ANOVAs) with repeated measures for canonical and scrambled order were conducted for both reaction times and error rates. The means and standard deviations were reported in Table 1. The results for correct "Yes" responses indicated that canonical sentences had shorter reaction times $\left[F_{1}(1,31)=19.517, p<.001 ; F_{2}(1\right.$, $35)=66.981, p<.001]$, and lower error rates $\left[F_{1}(1,31)=\right.$ $\left.10.148, p<.01 ; F_{2}(1,35)=19.386, p<.001\right]$ than the same sentences in scrambled order. Likewise, correct "No" responses showed the same result that canonical order resulted in shorter reaction times $\left[F_{1}(1,31)=9.859, p<.01 ; F_{2}(1.35)=8.345, p\right.$ $<.01]$ than the same sentences in scrambled order. However, no difference in error rates was noted $\left[F_{1}(1,31)=2.310, p=.139\right.$, ns; $F_{2}(1,35)=1.800, p=.188, n s$. $]$.

\section{Discussion}

Processing correct active sentences with transitive verbs showed significant scrambling effects in Experiment 1. This result provides evidence for existence of scrambling effects in

Table 1.

Reaction times and error rates for active sentences with transitive verbs.

\begin{tabular}{|c|c|c|c|c|c|}
\hline \multirow{2}{*}{$\begin{array}{c}\text { Response } \\
\text { Type }\end{array}$} & \multirow{2}{*}{$\begin{array}{c}\text { Sentence } \\
\text { Type }\end{array}$} & \multicolumn{2}{|c|}{ Reaction Time (ms) } & \multicolumn{2}{|c|}{ Error Rate $(\%)$} \\
\hline & & $\mathrm{M}$ & SD & $\mathrm{M}$ & SD \\
\hline "Yes" & SOV & 1291 & 254 & $2.43 \%$ & $3.14 \%$ \\
\hline Reponses & OSV & 1498 & 330 & $9.55 \%$ & $12.40 \%$ \\
\hline \multicolumn{2}{|c|}{ OSV-SOV } & 207 & $F_{1}{ }^{* * *} F_{2}{ }^{* *}$ & $7.12 \%$ & $F_{1}{ }^{* *} F_{2}{ }^{* *}$ \\
\hline "No" & SOV & 1436 & 390 & $12.15 \%$ & $13.79 \%$ \\
\hline Reponses & OSV & 1538 & 300 & $9.03 \%$ & $8.32 \%$ \\
\hline \multicolumn{2}{|c|}{ OSV-SOV } & 102 & $F_{1}{ }^{* *} F_{2}{ }^{* *}$ & $-3.13 \%$ & \\
\hline
\end{tabular}

Note: ${ }^{*} p<.05,{ }^{* *} p<.01,{ }^{* * *} p<.001$. 
written Sinhalese, supporting a configurational syntactic structure. An additional Experiment 2 was conducted to identify the same scrambling effects under the different condition of active sentences with ditransitive verbs.

\section{Experiment 2: Active Sentences with Ditransitive Verbs}

Experiment 2 used active sentences with ditransitive verbs as in nimala lalani-ta pādam kiyādunnēya meaning "Nimala helped Lalani with studies". These sentences can interchange three noun phrases in any order, so that five scrambled sentences can be produced on the basis of a single canonical order (SOOV). However, an inanimate noun in the third NP position was placed in the sentence-initial position in Experiment 2. For example, a canonical order of nimala lalani-ta pādam kiyādun$n \bar{e} y a$ [s NP-NOM (anim) [vp NP-DAT (anim) [vp NP-ACC (inam) V]]] was altered into its corresponding scrambled sentence pādam nimala lalani-ta kiyādunnēya [s NP-ACC (inam) [s NP-NOM (anim) [vp NP-DAT (anim) [vp gap ${ }_{1}$ V]]]]. Since both canonical and scrambled order sentences were constructed with identical lexical items, the sentences carry the same sentential meaning of "Nimala helped Lalani with studies". Only the syntactical structure was altered to investigate the scrambled effects.

\section{Participants and Procedure}

Refer to Experiment 1.

\section{Materials}

Experiment 2 examined active sentences containing ditransitive verbs as presented in Appendix B (sample of "Yes" responses). Thirty-six canonical ordered sentences for correct "Yes" responses were prepared like the example nimala lalanita pādam kiyādunnēya meaning "Nimala helped Lalani with studies". Based on these, the scrambled order sentences were created by putting the thirdly-positioned NP (e.g., pādam) into the sentence-initial position as in pādam nimala lalani-ta $k i$ $y \bar{a} d u n n \bar{e} y a$. With this procedure, 72 sentences for correct "Yes" responses were created. Again, the same strategy was used to make another 72 stimuli for the correct "No" responses with either syntactically or semantically incorrect sentences. For example, the canonical noun phrase order of amila wāhanayata banakêwèya meaning "Amila doctrine the vehicle" is scrambled as bana amila wāhanaya-ta kēweyya. In addition, another 28 sentences (14 canonical and 14 scrambled) were added as control sentences. As a result, a total of 172 stimuli were prepared for "Yes" and "No" responses. To avoid participants repeatedly seeing the same sentences in a different word order, a counterbalanced design was applied as in Experiment 1.

\section{Analysis and Results}

Extremes among sentence correctness decision times (less than $600 \mathrm{~ms}$ and longer than $6000 \mathrm{~ms}$ ) were recorded as missing values. Table 2 showed the means of correct "Yes" and "No" reaction times and error rates for sentence correctness decisions. The procedure and analysis employed the same as Experiment 1.

In Experiment 2, canonical sentences for correct "Yes" responses resulted in shorter reaction times $\left[F_{1}(1,31)=6.017, p\right.$
Table 2.

Reaction times and error rates for active sentences with ditransitive verbs.

\begin{tabular}{|c|c|c|c|c|c|}
\hline \multirow{2}{*}{$\begin{array}{l}\text { Response } \\
\text { Type }\end{array}$} & \multirow{2}{*}{$\begin{array}{l}\text { Sentence } \\
\text { Type }\end{array}$} & \multicolumn{2}{|c|}{ Reaction Time (ms) } & \multicolumn{2}{|c|}{ Error Rate (\%) } \\
\hline & & M & SD & M & SD \\
\hline "Yes" & $\mathrm{SO}_{1} \mathrm{O}_{2} \mathrm{~V}$ & 1562 & 367 & $6.25 \%$ & $11.70 \%$ \\
\hline Reponses & $\mathrm{O}_{2} \mathrm{SO}_{1} \mathrm{~V}$ & 1683 & 337 & $10.24 \%$ & $9.37 \%$ \\
\hline \multicolumn{2}{|c|}{$\begin{array}{c}\mathrm{O}_{2} \mathrm{SO}_{1} \mathrm{~V}-\mathrm{SO}_{1} \mathrm{O}_{2} \mathrm{~V} \\
\text { (Scrambling Effects) }\end{array}$} & 120 & $F_{1}^{*} F_{2}{ }^{* * *}$ & $3.99 \%$ & $F_{1}{ }^{*} F_{2}{ }^{*}$ \\
\hline "No" & $\mathrm{SO}_{1} \mathrm{O}_{2} \mathrm{~V}$ & 1643 & 362 & $18.06 \%$ & $13.01 \%$ \\
\hline Reponses & $\mathrm{O}_{2} \mathrm{SO}_{1} \mathrm{~V}$ & 1719 & 386 & $15.28 \%$ & $9.98 \%$ \\
\hline \multicolumn{2}{|c|}{$\begin{array}{c}\mathrm{O}_{2} \mathrm{SO}_{1} \mathrm{~V}-\mathrm{SO}_{1} \mathrm{O}_{2} \mathrm{~V} \\
\text { (Scrambling Effects) }\end{array}$} & 77 & $F_{1}^{*} F_{2}$ n.s. & $-2.78 \%$ & \\
\hline
\end{tabular}

Note: ${ }^{*} p<.05 ;{ }^{* *} p<.01 ;{ }^{* * *} p<.001$.

$\left.<.05 ; F_{2}(1,35)=14.494, p<.001\right]$, and lower error rates $\left[F_{1}(1\right.$, $\left.31)=5.001, p<.05 ; F_{2}(1,35)=6.740, p<.05\right]$ than scrambled sentences. In contrast, for correct "No" responses, a difference was found between the reaction times of canonical and scrambled sentences in participant analysis $\left[F_{1}(1,31)=4.836, p\right.$ $<.05]$, but not in item analysis $\left[F_{2}(1,35)=3.646, p=.064, n s\right.$. $]$. Error rates were not significant $\left[F_{1}(1,31)=1.494, p=.231, n s\right.$.; $\left.F_{2}(1,35)=0.947, p=.337, n s.\right]$.

\section{Discussion}

In addition to Experiment 1, Experiment 2 also provided evidence for the existence of scrambling effects in active sentences with ditransitive verbs. Thus, the existence of a configurational syntactic structure was supported in written Sinhalese, which leads us the second question. What kind of information cues do native Sinhalese speakers use to identify the canonical order in written Sinhalese?

\section{Experiment 3: Passive Sentences with Transitive Verbs}

Experiment 3 employed passive sentences with transitive verbs. Sentences such as niila wisin samara-ta gasanulebuwāya [s NP-NOM [vp NP-DAT V]], ("Samara was hit by Niila") are altered to make scrambled order sentences by relocating the dative noun phrase (samara-ta) to the initial position of the sentence samara-ta niila wisin gasanulebuwāya [S $_{\mathrm{SP}-\mathrm{DAT}_{1}}$ NP-NOM [vP gap $\left.\left._{1} \mathrm{~V}\right]\right]$. Both canonical and scrambled sentences fundamentally carry the same meaning of "Samara was hit by Niila". In passive sentences, thematic roles and case markers provide a conflicting picture of their word orders. The canonical order assumed by thematic roles indicates that an agent should precede the theme (i.e., samara-ta niila wisin gasanulebuwāya). Contrarily, the canonical order assumed by case particles indicates that an NP followed by ablative wisin particle should placed in the initial position of the sentence, followed by another NP accompanied by the dative case marker - $t a$ (i.e., niila wisin samara-ta gasanulebuwāya). Therefore, it is hoped that, on the processing of passive sentences, Experiment 3 offers evidence as to which information cue (thematic roles or case particles) is actually used by native Sinhalese speakers.

\section{Participants and Procedure}

Refer to Experiment 1. 


\section{Materials}

Experiment 3 used passive sentences, a sample of which is shown in Appendix C (sample of "Yes" responses). First, 30 canonical ordered sentences for correct "Yes" responses were selected as in niila wisin samara-ta gasanulebuwāya meaning "Samara was hit by Nimala". Based on these, the scrambled order sentences were altered by moving the NP with dative -ta to the sentence-initial position as in samara-ta niila wisin gasanulebuwāya. As a result, 60 sentences were created for correct "Yes" responses. Using the same procedure, another 60 stimuli were produced for the correct "No" responses containing either a syntactic or semantic error. In addition, another 24 sentences (12 canonical and 12 scrambled) were added as control sentences. To avoid participants repeatedly seeing the same sentences in a different word order, a counterbalanced design was applied as in Experiments 1 and 2.

\section{Analysis and Results}

Extremes among sentence correctness decision times (less than $500 \mathrm{~ms}$ and longer than $5000 \mathrm{~ms}$ ) were recorded as missing values. Table 3 showed the means of correct "Yes" and "No" reaction times and error rates for sentence correctness decisions. The procedure and analysis were the same as the previous experiments.

In Experiment 3, SOV ordered passive sentences for correct "Yes" responses showed shorter reaction times $\left[F_{1}(1,31)=\right.$ $\left.10.132, p<.01 ; F_{2}(1,29)=19.209, p<.001\right]$ and lower error rates $\left[F_{1}(1,31)=21.381, p<.001 ; F_{2}(1,29)=33.278, p<.001\right]$ than those with scrambled order (OSV). In contrast, for correct 'No' responses, neither reaction times $\left[F_{1}(1,31)=2.832, p\right.$ $\left.=.102, n s . ; F_{2}(1,29)=4.046, p=.054, n s.\right]$ nor error rates $\left[F_{1}(1\right.$, $31)=3.414, p=.453, n s . ; F_{2}(1,29)=4.083, p=.053, n s$. $]$ showed significance.

\section{Discussion}

Results of Experiment 3 indicated that the canonical order identified by case particles in which NP with the ablative case marker -wisin precedes a NP with the dative case marker -ta was more quickly processed for sentence correctness decisions than the canonical order identified by thematic roles. Therefore, thematic roles can be excluded as a major cue of priority information; consequently, the remaining information cues, case

Table 3.

Reaction times and error rates for passive sentences with transitive verbs.

\begin{tabular}{|c|c|c|c|c|c|}
\hline \multirow{2}{*}{$\begin{array}{c}\text { Response } \\
\text { Type }\end{array}$} & \multirow{2}{*}{$\begin{array}{c}\text { Sentence } \\
\text { Type }\end{array}$} & \multicolumn{2}{|c|}{ Reaction Time (ms) } & \multicolumn{2}{|c|}{ Error Rate (\%) } \\
\hline & & M & SD & $\mathrm{M}$ & SD \\
\hline "Yes" & SOV & 1696 & 331 & $2.71 \%$ & $3.33 \%$ \\
\hline Response & OSV & 1788 & 311 & $12.29 \%$ & $12.11 \%$ \\
\hline \multicolumn{2}{|c|}{$\begin{array}{c}\text { OSV-SOV } \\
\text { (Scrambling Effects) }\end{array}$} & 92 & $F_{1}{ }^{* *} F_{2}{ }^{* * *}$ & $9.58 \%$ & $F_{1}{ }^{* * *} F_{2}{ }^{* *}$ \\
\hline "No" & SOV & 1737 & 372 & $9.17 \%$ & $10.54 \%$ \\
\hline Response & OSV & 1686 & 383 & $5.00 \%$ & $7.76 \%$ \\
\hline \multicolumn{2}{|c|}{$\begin{array}{c}\text { OSV-SOV } \\
\text { (Scrambling Effects) }\end{array}$} & -51 & & $-4.17 \%$ & \\
\hline
\end{tabular}

particles and grammatical functions, were taken into consideration for revealing the priority information for identifying canonical order used by native Sinhalese speakers.

\section{Experiment 4: Potential Sentences}

Since Experiment 3 excluded thematic roles as a major cue of the priority information for canonical order, Experiment 4 was conducted focusing on the two remaining information cues, case particles and grammatical functions. Potential sentences such as nimala-ta japan kathākiriime hekiyāwaketha [s NPDAT [vP NP-NOM V + POT]] meaning "Nimala speaks Japanese" were altered to create the corresponding scrambled sentences as in japan nimala-ta kathākiriime hekiyāwaketha [s $\mathrm{NP}^{-N O M}{ }_{1}\left[\mathrm{vp}\right.$ NP-DAT [vP gap $\left.\left._{1} \mathrm{~V}+\mathrm{POT}\right]\right]$ ]. In potential sentences, the dative case marker $-t a$ is assigned to a grammatical subject. Grammatical functions require that a subject with $-t a$ comes before the object in the canonical order as in nimala-ta japan kathākiriime hekiyāwaketha [s NP-DAT [vP NP-NOM V + POT]]. On the other hand, the canonical order assumed by case particles suggests a dative case marker -ta should precede the predicate as in japan nimala-ta kathākiriime hekiyāwaketha [s NP-NOM ${ }_{1}$ [vp NP-DAT [vp gap $\left.\left._{1} \mathrm{~V}+\mathrm{POT}\right]\right]$ ]. If canonical order is identified by grammatical functions (i.e., SOV are processed faster and more accurately than the OSV scrambled order), grammatical functions will prove to be the last remaining priority information in written Sinhalese. In contrast, if the canonical order is identified by the case particles (i.e., OSV are processed faster and more accurately than the SOV scrambled order), the case particles will provide the priority information in written Sinhalese.

\section{Participants}

Thirty native Sinhalese speakers (26 male and 4 female) residing in Aichi prefecture, Japan participated in Experiment 4. All of them participated in Experiments 1-3. However, due to a mechanical trouble, data of two participants were not recorded. Ages ranged from 23 years and 6 months to 46 years and 2 months, with the average age being 32 years and 2 months on the day of testing.

\section{Procedure}

Refer to Experiment 1.

\section{Materials}

Experiment 4 used potential sentences (refer to Appendix D for a sample of "Yes" responses). First, 24 canonical ordered sentences for correct "Yes" responses were selected as in $n i$ mala-ta japan kathākiriimehekiyāwaketha meaning "Nimala can speak Japanese". Based on these, the scrambled order sentences were relocated by moving the secondly-positioned NP to the sentence-initial position (japan nimala-ta kathākiriimehekiyāwaketha). As a result, 48 sentences were created for correct "Yes" responses. Using the same procedure, another 48 stimuli were created for the correct "No" responses containing either a syntactic or semantic error. In addition, another 20 sentences (10 canonical and 10 scrambled) were added as control sentences. To avoid participants repeatedly seeing the same sentences in a different word order, a counterbalanced design was applied as in the previous experiments. 


\section{Analysis and Results}

Extremes among sentence correctness decision times (less than $500 \mathrm{~ms}$ and longer than $5000 \mathrm{~ms}$ ) were recorded as missing values. Table 3 error rates for sentence correctness decisions. The procedure and analysis were the same as the previous experiments. Table 4 shows the means and standard deviations for correct "Yes" and "No" reaction times and error rates for sentence correctness decisions.

In Experiment 4, SOV ordered potential sentences showed shorter reaction times for correct "Yes" responses $\left[F_{1}(1,29)=\right.$ $\left.4.885, p<.05 ; F_{2}(1,23)=8.288, p<.01\right]$ and lower error rates $\left[F_{1}(1,29)=8.863, p<.01 ; F_{2}(1,23)=5.035, p<.05\right]$ than those with scrambled order of OSV. For correct "No" responses, canonical order did not show faster reaction times than scrambled order in participant analysis $\left[F_{1}(1,29)=4.067, p=.053\right.$, $n s$.$] , but was significant in item analysis \left[F_{2}(1,23)=6.873, p\right.$ $<.05]$, whereas no difference was found in error rates $\left[F_{1}(1,29)\right.$ $=1.543, p=224, n s$.; $\left.F_{2}(1,23)=1.657, p=.211, n s.\right]$.

\section{Discussion}

The results of Experiment 4 indicated that the processing of potential sentences based on grammatical functions word order (i.e., SOV) required shorter reaction times and lower error rates than the word order identified by the case particles (i.e., OSV).Therefore, considering all the results of Experiments 1 to 4 , it can be concluded that grammatical functions are the remaining priority information in written Sinhalese.

\section{General Discussion}

The present study investigated priority information used by native Sinhalese speakers. As shown in Table 5, the three kinds of information of thematic roles, case particles, and grammatical functions provide different cues to canonical order. Thematic roles requires agent to precede theme and goal. Case

Table 4.

Reaction times and error rates for potential sentences.

\begin{tabular}{|c|c|c|c|c|c|}
\hline \multirow{2}{*}{$\begin{array}{c}\text { Response } \\
\text { Type }\end{array}$} & \multirow{2}{*}{$\begin{array}{l}\text { Sentence } \\
\text { Type }\end{array}$} & \multicolumn{2}{|c|}{ Reaction Time (ms) } & \multicolumn{2}{|c|}{ Error Rate $(\%)$} \\
\hline & & $\mathrm{M}$ & SD & $\mathrm{M}$ & SD \\
\hline "Yes" & SOV & 1492 & 304 & $4.44 \%$ & $6.09 \%$ \\
\hline Response & OSV & 1568 & 335 & $11.39 \&$ & $14.60 \%$ \\
\hline \multicolumn{2}{|c|}{$\begin{array}{c}\text { OSV-SOV } \\
\text { (Scrambling Effects) }\end{array}$} & 77 & $F_{1}{ }^{*} F_{2}{ }^{* *}$ & $7 \%$ & $F_{1}{ }^{* *} F_{2}{ }^{*}$ \\
\hline "No" & SOV & 1609 & 394 & $8.33 \%$ & $9.02 \%$ \\
\hline Response & OSV & 1687 & 280 & $11.11 \%$ & $10.57 \%$ \\
\hline \multicolumn{2}{|c|}{$\begin{array}{c}\text { OSV-SOV } \\
\text { (Scrambling Effects) }\end{array}$} & 78 & $F_{1}$ n.s. $F_{2}{ }^{*}$ & $2.78 \%$ & \\
\hline
\end{tabular}

Note: ${ }^{*} p<.05 ;{ }^{* *} p<.01 ;{ }^{* * *} p<.001$.

Table 5.

Predicted canonical order by information cues

\begin{tabular}{cc}
\hline Information Cues & Canonical Word Order \\
\hline Thematic Roles & Agent $>$ Theme $>$ Goal \\
Case Particles & Nominative $>$ Dative $>$ Accusative \\
Grammatical Functions & Subject $>$ Object $>$ Verb \\
\hline
\end{tabular}

particles offers a cue that nominative comes before dative and accusative. Grammatical functions provide information that subject comes before object.

Processing grammatically and semantically acceptable sentences (correct "Yes" responses) showed consistently significant scrambling effects in each of the four experiments. In Experiment 1 , OSV scrambled sentences resulted in longer reaction times compared to SOV canonical sentences. In addition, Experiment 2 also showed that OSOV scrambled sentences take longer to process than SOOV canonical sentences. The results of Experiments 1 and 2 provided evidence for scrambling effects in written Sinhalese. Thus, as previous studies (Dissanayaka, 2007; Herath, Hyodo, Kawada, Ikeda, \& Herath, 1994; Pallatthara \& Weihene, 1966; Tamaoka et al., 2011) indicated, both experiments in the present study also showed that the canonical word order in the Sinhalese language is SOV.

However, thematic roles, case particles and grammatical functions provide the same information for canonical order in active Sinhalese written sentences. For example, in the sentence amara nimala-ta gehuwēya meaning "Amara hit Nimala", case particles indicate that the nominative NP is always marked by empty $(\varphi)$, and the accusative NP always precedes the casemarker - $t a$ (which is dative, but functions like an accusative) in an active sentence which contains a transitive verb. Secondly, thematic roles suggest as an agent (amara) always precedes a theme (nimala), so that the sentence can be interpreted as the agent Amara hits Nimala. Finally, grammatical functions suggest that the word order should be organized as subject $\mathrm{S}$ (amara) object O (nimala-ta) and verb V (gehuwēya). To identify the priority information applicable to a variety of sentence types, two further experiments were conducted to single out the universal information cue.

Passive sentences display conflict between the information for canonical word order provided by thematic roles and case particles. Therefore, Experiment 3 is aimed at comparing the processing of canonical order defined by thematic roles and case particles in the processing of passive sentences. Results of Experiment 3 showed that native Sinhalese speakers processed passive sentences with SOV canonical word order defined by case particles more quickly and accurately than OSV order defined by thematic roles. Thus, native Sinhalese speakers rely on the information provided by the case particles when processing passive sentences. Experiment 3 excluded thematic roles as the priority information. Thus, Experiment 4 investigated the remaining two cues, case particles and grammatical functions.

In Experiment 4, native speakers processed SOV potential sentences defined by grammatical functions more quickly and accurately than OSV, were the information is provided by case particles. Therefore, Experiment 4 revealed that native Sinhalese speakers use the information given by grammatical function (plural) rather than case particles for the processing of potential sentences. The present study concluded grammatical functions as the most universal information cue for canonical word order among thematic roles, case particles, and grammatical functions for written Sinhalese sentences.

To conclude, as found in the Japanese language (Tamaoka et al., 2005), grammatical functions clearly provide adequate information for native speakers to determine canonical order in various types of written Sinhalese sentences. Grammatical functions must offer crucial information which delivers cues for canonical order for various languages. 


\section{Acknowledgements}

We are grateful to anonymous reviewers for their invaluable comments and suggestions. The study reported here was partially supported by Grants-in-Aid for Scientific Research (No. 23320106 and No. 22222001) from the Japanese Ministry of Education, Culture, Sports, Science, and Technology.

\section{REFERENCES}

Dissanayaka, J. B. (2007). Say it in Sinhala. Colombo, Sri Lanka: Stamford Lake Publication.

Englebretson, R., \& Genetti, C. (Eds.) (2005). Santa Barbara papers in linguistics: Proceeding from the workshop on Sinhala linguistics. Santa Barbara: Department of Linguistics, University of California.

Gair, W. J. (1998). Syntax: Configuration, order, and grammatical function. In L. C. Barbara (Ed.), Studies in South Asian linguistics: Sinhala and other South Asian languages (pp. 47-110). New York: Oxford University Press.

Herath, A., Hyodo, Y., Kawada, Y., Ikeda, T., \& Herath, S. (1994). A practical machine translation system from Japanese to modern Sinhalese. Gifu: Gifu University, 153-162.

Koizumi, M., \& Tamaoka, K. (2004). Cognitive processing of Japanese sentences with ditransitive verbs. Gengo Kenkyu (Journal of the Linguistic Society of Japan), 125, 173-190.

Koizumi, M., \& Tamaoka, K. (2010). Psycholinguistic evidence for the VP-internal subject position in Japanese. Linguistic Inquiry, 41, 663-
680. doi:10.1162/LING a 00016

Mazuka, R., Itoh, K., \& Kondo, T. (2002). Cost of scrambling in Japanese sentence processing. In M. Nakayama (Ed.), Sentence processing in East-Asian languages (pp. 131-166). Stanford, CA: CSLI (Center for the Study of Language and Information).

Miyamoto, E. T., \& Takahashi, S. (2004). Filler-gap dependencies in the processing of scrambling in Japanese. Language and Linguistics, 5, 153-166.

Miyagawa, S. (2003). A movement scrambling and options without optionality. In S. Karimi, (Ed.), Word order and scrambling. Oxford: Blackwell Publishing Ltd. doi:10.1002/9780470758403.ch8

Miyagishi, T. (2003). Relationship between ablative/instrumental case nouns. Yasuda Women's University Bulletin, 31, 1-26.

Miyagishi, T. (2005). Accusative subject of subordinate clause in Sinhalese. Yasuda Women's University Bulletin, 33, 15-26.

Pallatthara, S., \& Weihene, P. (1966). Sinhala grammar in linguistic perspective. Colombo: S. Godage \& Brothers.

Ross, J. R. (1967). Constraints on variables in syntax. Ph.D. Thesis, Cambridge: Massachusetts Institute of Technology.

Tamaoka, K., Sakai, H., Kawahara, J., Miyaoka, Y., Lim, H., \& Koizumi, M. (2005). Priority information used for the processing of Japanese sentences: Thematic roles, case particles or grammatical functions. Journal of Psycholinguistic Research, 34, 273-324. doi:10.1007/s10936-005-3641-6

Tamaoka, K., Kanduboda, A. B. P., \& Sakai, H. (2011). Effects of word order alternation on the sentence processing of Sinhalese written and spoken forms. Open Journal of Modern Linguistics, 1, 24-32. doi:10.4236/ojml.2011.12004 


\section{Appendix A: A Sample List of Active Sentences Consisting of Transitive Verbs in Experiment 1}

Experiment 1 used 36 canonical ordered sentences for correct YES responses as exemplified below. Based on these sentences, 36 scrambled sentences were built. The secondly positioned noun (ACC) is placed in the sentence initial position in order to make scrambled order sentences.

1 kamala niila-ta hondakiwwaaya

Kamala ( $\varphi$ NOM, anim) Niila (ACC, anim) praise (V + PST)

Kamala praised Niila.

2 guruthuma daruwanta igennuweaya

teacher ( $\varphi$ NOM, anim) children (ACC, anim)

teach (V + PST)

The teacher educated the children.

3 gayaani niila-ta bennaaya

Gayani ( $\varphi$ NOM, anim) Niila (ACC, anim) scold (V + PST)

Gayani scolded Niila.

4 amila ganga-ta andagehuweaya

Amila ( $\varphi$ NOM, anim) Ganga (ACC, anim) call (V + PST)

Amila called Ganga.

5 mallii nayaa-ta gehuweaya

younger brother ( $\varphi$ NOM, anim) snake (ACC, anim)

Hit (V + PST)

Younger brother hit the snake.

\section{Appendix B: A Sample List of Active Sentences Consisting of Ditransitive Verbs in Experiment 2}

Experiment 2 used 36 canonical ordered sentences for correct YES responses as exemplified below. Another 36 sentences for scrambled order were constructed based on these sentences. The thirdly positioned noun (ACC) is placed in the sentence initial position in order to make scrambled sentences.

1 guruthuma lamayata paadam kiyaadunneaya

teacher $(\varphi \mathrm{NOM}$, anim) student (DAT, anim)

lesson $(\varphi \mathrm{ACC}$, inam) teach $(\mathrm{V}+\mathrm{PST})$

The teacher taught lessons to the student.

2 gayakayaa rasikayanta giitha kiiwaaya

singer ( $\varphi$ NOM, anim) listners (DAT, anim)

songs ( $\varphi$ ACC, inam) sing (V + PST)

The singer sang a song for the audience.

3 ayyaa mata potak dunneaya

elderbrother ( $\varphi$ NOM, anim) me (DAT, anim)

book $(\varphi \mathrm{ACC}$, inam) give $(\mathrm{V}+\mathrm{PST})$

Elder brother gave me a book.

4 akkaa mallita salli dunnaaya

elder sister ( $\varphi$ NOM, anim) younger brother (DAT, anim)

money $(\varphi \mathrm{ACC}$, inam) give $(\mathrm{V}+\mathrm{PST})$

Elder sister gave money to younger brother.

5 horu apata boru kiiweaya

thieves ( $\varphi$ NOM, anim) us (DAT, anim) lie ( $\varphi$ ACC, inam)

tell (V + PST)

The thieves lied to us.

\section{Appendix C: A Sample List of Passive Sentences Consisting Transitive Verbs in Experiment 3}

Experiment 3 used 30 canonical ordered sentences for correct YES responses as exemplified below. Based on these sentences, 30 scrambled sentences were constructed. The secondly positioned noun (DAT) is placed in the sentence initial position to make scrambled order sentences.

1 ammaa wisin apata kiribath hadanu lebuweaya

mother (NOM, anim) us (DAT, anim)

milkrice $(\varphi \mathrm{ACC}$, inam) make $(\mathrm{V}+\mathrm{PASS}+\mathrm{PST})$

The milk rice was made by mother.

2 thaththaa wisn apata paadam kiyadenulebuweaya

father (NOM, anim) us (DAT, anim) lessons ( $\varphi$ ACC, inam)

teach $(\mathrm{V}+\mathrm{PASS}+\mathrm{PST})$

The lessons were taught by father.

3 malli wisin nangita akuru uganwanu lebuweaya younger brother (NOM, anim) younger sister (DAT, anim) letters $(\varphi \mathrm{ACC}$, inam) help $(\mathrm{V}+\mathrm{PASS}+\mathrm{PST})$

Younger sister was helped by younger brother to read letters.

4 maamaa wisin apata liyumak liyanu lebuweaya uncle (NOM, anim) us (DAT, anim) letter ( $\varphi$ ACC, inam) write (V + PASS + PST)

The letter was written by our uncle.

5 ruwan wisin akkata pariganakaya hadaadenu lebuweaya

Ruwan (NOM, anim) elder sister (DAT, anim)

computer $(\varphi \mathrm{ACC}$, inam) repair $(\mathrm{V}+\mathrm{PASS}+\mathrm{PST})$

The computer was repaired by Ruwan.

\section{Appendix D: A Sample List of Potential Sentences Used in Experiment 4}

Experiment 4 used 24 canonical ordered sentences for correct YES responses as exemplified below. Based on these sentences, another 24 sentences were constructed for the scrambled order sentences. The secondly positioned noun (NOM) is placed in the sentences initial position in order to make scrambled order sentences.

1 nangita piinanna hekiyāwaketha

younger sister (DAT, anim) swim ( $\varphi \mathrm{NOM}$, inam) can $(\mathrm{V}+\mathrm{PRE})$

Younger sister can swim.

2 amālita chitraandinna hekiyāwaketha

Amali (DAT, anim) art + draw ( $(\mathrm{NOM}$, inam) can $(\mathrm{V}+\mathrm{PRE})$

Amali can draw pictures.

3 chiitata duwanna hekiyāwaketha

cheetah (DAT, anim) run ( $\varphi$ NOM, inam) can $(\mathrm{V}+\mathrm{PRE})$

The cheetah can run.

4 ajithta criketgahanna hekiyāwaketha

Ajith (DAT, anim) cricket+play ( $\varphi$ NOM, inam)

can (V + PRE)

Ajith can play cricket.

5 sangiithata natanna hekiyāwaketha

Sangiitha (DAT, anim) dance ( $\varphi$ NOM, inam) can $(V+P R E)$

Sangiitha can dance. 